\title{
Percutaneous Cholecystostomy in High-risk Geriatric Patients with Acute Cholecystitis
}

\author{
Hasan Gündoğdu and Gokhan Demiral ${ }^{2}$ \\ ${ }^{1}$ Department of Radiology, Recep Tayyip Erdogan University, Rize, Turkey \\ ${ }^{2}$ Department of General Surgery, Recep Tayyip Erdogan University, Rize, Turkey
}

\begin{abstract}
Objective: To determine the results of high-risk geriatric patients treated with percutaneous cholecystostomy (PC) for acute cholecystitis (AC).

Study Design: Observational study.

Place and Duration of Study: Department of Interventional Radiology, Recep Tayyip Erdogan University Hospital, Rize, Turkey, from April 2015 to October 2020.

Methodology: Seventy-four patients, who underwent PC with a diagnosis of AC, were divided into three groups according to their ages: 65-74 years as group I, 75-84 years as group II, and $\geq 85$ years as group III. Groups were compared in terms of American Society of Anesthesiologists (ASA) score, Charlson Comorbidity Index (CCl), technical success, clinical success, complications, need for cholecystectomy, duration of hospital stay, 30 and 90 days mortality, catheter removal time, and recurrent cholecystitis after catheter insertion.

Results: Technical success was $100 \%$ in all groups. Clinical success decreased with age. There was a positive correlation between the patients' ASA score and age $(p<0.001)$. The duration of hospital stay increased with age $(p=0.049)$. ASA score was found to be an independent risk factor in predicting overall survival (HR: 4.748; $95 \% \mathrm{Cl}: 1.030-21.895 ; p=0.046$ ). The mean catheter removal time was the longest in group III, and there was a significant difference between the groups ( $p$ $<0.001)$. A significant positive correlation was found between catheter removal time and $\mathrm{CCl}(\mathrm{p}<0.001)$. There was no statistically significant difference between groups in terms of complications and recurrent cholecystitis.

Conclusion: PC can be considered as definitive treatment in advanced elderly patients and interval therapy in early old age.
\end{abstract}

Key Words: Acute cholecystitis, Elderly, Percutaneous cholecystostomy.

How to cite this article: Gündoğdu H, Demiral G. Percutaneous Cholecystostomy in High-risk Geriatric Patients with Acute Cholecystitis. J Coll Physicians Surg Pak 2021; 31(07):770-774.

\section{INTRODUCTION}

Old age is defined chronologically as the beginning of age 65 by the World Health Organization (WHO) and is divided into three subgroups. ${ }^{1}$ One of the most common surgical emergencies in elderly patients is acute cholecystitis (AC). ${ }^{2}$

$\mathrm{AC}$ is a common disease and can lead to complications such as empyema, gangrene, perforation, bileleakage, abscess formation, pericholecystitis, peritonitis, sepsis and death. Its incidence increases with age and those with a higher rate of systemic comorbidity.

Correspondence to: Dr. Hasan Gündoğdu, Department of Radiology, Recep Tayyip Erdogan University, Rize, Turkey E-mail: drhasangundogdu@gmail.com

Received: April 12, 2021; Revised: May 27, 2021; Accepted: June 19, 2021

DOI: https://doi.org/10.29271/jcpsp.2021.07.770
Basic factors determining the treatment to be applied include the patient's age, comorbidities, the associated Charlson comorbidity Index $(\mathrm{CCl})$ and the American Society of Anesthesiologists-Physical Condition Classification (ASA-PC) scores, AC severity index, and the time between the onset of the event and presentation. $^{3}$

In the treatment of AC, early laparoscopic cholecystectomy (LC) is the most appropriate treatment in patients eligible for surgery. ${ }^{4}$ However, elderly patients with comorbidities may not tolerate surgical intervention as perioperative mortality may reach up to $19 \%{ }^{5}$ The World Society of Emergency Surgery (WSES) 2016 clinical guidelines consider that patient age over 80 years is a risk factor for worse clinical development, morbidity and mortality in acute cholecystitis. ${ }^{6}$ Therefore, elderly and high-risk patients with $\mathrm{AC}$ are usually treated with conservative methods such as intravenous fluid, antibiotic therapy, and percutaneous cholecystostomy (PC), while surgical intervention is delayed for 6-8 weeks. ${ }^{7,8}$ Intravenous fluid and antibiotic therapy fail to improve clinical signs in most of these patients. Therefore, it may require rapid decompression of the gallbladder. ${ }^{9}$ 
PC has been shown to improve mortality in high-risk patients, and its use has increased in recent years as an alternative therapy for AC. ${ }^{10,11}$ Although there are many studies aboutpercutaneous cholecystostomy in the literature, there are very few studies evaluating the efficacy, safety, recurrence rates, need for re-intervention, and complications of PC in the treatment of AC in high-risk geriatric age groups.

The aim of this study was to investigate the effectiveness and reliability of PC in high-risk geriatric age groups.

\section{METHODOLOGY}

In the Interventional Radiology Department, Recep Tayyip Erdogan University Hospital, Rize, Turkey, the data of patients aged 65 and over who underwent PC with a diagnosis of AC between April 2015 and October 2020, were retrospectively analysed by scanning the hospital information processing system. Approval was obtained from the Clinical Research Ethics Committee of Recep Tayyip Erdoğan University, Faculty of Medicine. Informed consent form could not be obtained from the patients due to the restrospective design of the study.

Diagnosis of AC, postive Murphy's sign as a sign of local inflammation or right upper quadrant pain, fever with systemic inflammation or one of the elevated C-reactive protein or elevated white blood cell count, characteristic imaging findings of AC [abdominal ultrasonography (US), computed tomography and magnetic resonance cholangiopancreatography] such as the 2013 criteria of the Tokyo guideline, ${ }^{12}$ were the inclusion Criteria. PC indications in patients with acute cholecystitis were surgery, due to high risk-related severe comorbidity (ASA $\geq 3$ ), severe cholecystitis that did not respond to conservative treatment, and patients who refused cholecystectomy.

The 74 patients meeting the criteria were grouped according to their ages as group 1 (65-74 years), group 2 (75-84 years), and group 3 ( $\geq 85$ years). The groups consist of 26,26 , and 22 patients, respectively-

Patient groups undergoing PC were compared in terms of gender, ASA score, $\mathrm{CCl}$, technical success, clinical success, complications, emergency and elective cholecystostomy need, duration of hospital stay, 30- and 90-day mortality, catheter removal time, recurrent cholecystitis occurence after catheter.

Empirically, intravenous antibiotic and fluid therapy for Gram (-) bacteria was initiated in all patients with AC after the diagnosis. $\mathrm{PC}$ was performed by the interventional radiologist under local anesthesia, with the addition of sedoanalgesia to some patients, by inserting a locked pigtail 8 French catheter into the gallbladder transhepatically with the Seldinger method, US and fluoroscopy. The first sample was sent to microbiology; and medical treatment was arranged, according to the antibiogram. The daily drainage of the patients was followed and re-evaluated clinically and by US, when necessary.

Technical success was defined as the demonstration of the correct placement of the PC tube in the gallbladder lumen, using contrast agent under fluoroscopy after ultrasonography. Clin- ical success was considered to be the relief of symptoms at the time of admission, and the decrease in body temperature, C-reactive protein or white blood cell count within three days, and discharge from the hospital without the need for emergency surgery at the first admission.

PC-related perioperative complications were recorded and classified, according to the Society of Interventional Radiology Guidelines. Patients' cholecystostomy catheters were retained for at least three weeks; After the patient was asymptomatic, the gallbladder size and wall thickness were normal in ultrasonography; and the cystic duct was open on the cholangiogram, the catheter was removed by the authors in all patients.

After the PC catheter was removed, the patients were followed up clinically and, if necessary, radiologically.

The research data were loaded with Windows 23.0 SPSS (Statistical Package for Social Sciences) and MedCalc ${ }^{\circledR}$ Statistical Software version 19.8 (MedCalc Software Ltd, Ostend, Belgium; http://www.medcalc.org; 2021) and evaluated. Descriptive statistics of the groups were reported as frequencies and percentages within the groups $(n, \%)$. Before analysing the relationship of continuous numerical variables between groups, they were subjected to normality analysis. Accordingly, variables with normal distribution were reported as mean \pm standard deviation, and variables that did not show normal distribution were reported as the median (IQR: 25th percentile-75th percentile). For the difference analysis in terms of numerical variables between the groups, the means were compared with One-way ANOVA analysis for the parameters showing normal distribution. Post-hoc Tukey HSD was applied for parameters, for which significance was determined. KruskalWallis test was used for numerical variables that did not show normal distribution. Post-hoc Bonferroni correction was applied for parameters, for which significance was determined. The difference in the distribution of categorical data between groups was evaluated with the Chi-square test. To examine the relationship between numerical data, the rho correlation coefficients were reported using Spearman correlation analysis. Independent predictor factors, affecting survival in patients who underwent cholecystostomy, were determined by performing survival analysis with Cox regression and log-rank analyses and Kaplan Meier charts. Factors with a significance of $p<0.10$ as a result of univariate Cox regression analysis were added to the model to be created to determine independent predictors for overall survival. The factors that make up the final model were determined with the backward stepwise method. A p-value of $<0.05$ was considered as significant.

\section{RESULTS}

A total of 74 patients were included in the study. The number of patients was 26, 26 and 22 for groups I, II and III, respectively. The demographic characteristics of the patients are summarised in Table I.

In terms of gender, women were more in group II and III than in group I, but there was a significant difference only in group III (p:0.031). 
Table I: Distribution of patients, according to age groups by gender, ASA score and CCI.

\begin{tabular}{|c|c|c|c|c|c|}
\hline & $65-74$ years & $75-84$ years & $\geq 85$ years & \multirow[b]{2}{*}{ p-value* } \\
\hline & & $\begin{array}{c}n(\%) \\
\text { median(25thP-75thP) }\end{array}$ & $\begin{array}{c}\mathrm{n}(\%) \\
\text { median (25thP-75thP) }\end{array}$ & $\begin{array}{c}\mathrm{n}(\%) \\
\text { median (25thP-75thP) }\end{array}$ & \\
\hline \multirow{2}{*}{ Gender } & Female & $9(23.1)$ & $14(35.9)$ & $16(41)$ & \multirow{2}{*}{0.031} \\
\hline & Male & $17(48.6)$ & $12(34.3)$ & $6(17.1)$ & \\
\hline \multirow{2}{*}{ ASA score } & 3 & $24(53.3)$ & $14(31.1)$ & 7 (15.6) & \multirow{2}{*}{$<0.001$} \\
\hline & 4 & $2(6.9)$ & $12(41.4)$ & $15(51.7)$ & \\
\hline \multicolumn{2}{|l|}{$\mathrm{CCl}$} & $5(4-6)$ & $7(6-8)$ & $8(8-9)$ & $<0.001$ \\
\hline
\end{tabular}

Table II: Spearman correlation analysis of ASA score, $\mathrm{CCl}$, duration of hospital stay and age.

\begin{tabular}{|c|c|c|c|c|c|}
\hline & & ASA Score & $\mathrm{CCl}$ & Duration of hospital & Age \\
\hline \multirow{2}{*}{ ASA Score } & rho & 1.000 & .715 & 0.211 & .508 \\
\hline & $p$-value & & $<0.001$ & 0.072 & $<0.001$ \\
\hline \multirow{2}{*}{$\mathrm{CCl}$} & rho & & 1.000 & 0.222 & .848 \\
\hline & $p$-value & & & 0.057 & $<0.001$ \\
\hline \multirow{2}{*}{ Dur. of Hosp. } & rho & & & 1.000 & .230 \\
\hline & $p$-value & & & & 0.049 \\
\hline
\end{tabular}

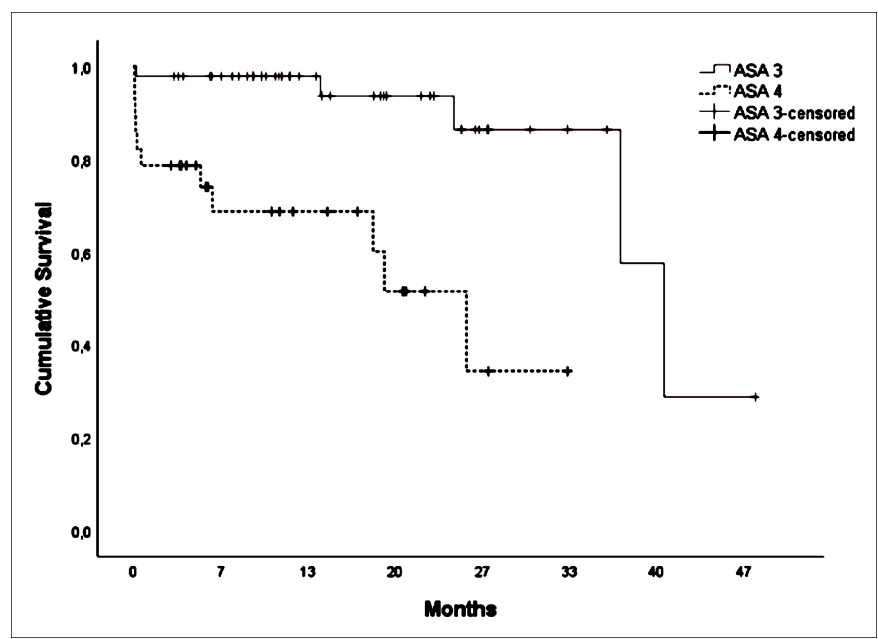

Figure 1: Kaplan-Meier overall survival plot for ASA score.

Technical success was $100 \%$ in all groups and there was no difference between the groups.

Clinical success was $96.2 \%(n: 25)$ in group I, $92.3 \%(n: 24)$ in group II, and $77.3 \%$ (n:17) in group III. Although the clinical success between the groups was not statistically significant $(p=0.090)$, the clinical success in group III was lower.

Perioperative complication rate was $18.9 \%(n: 14)$ in total; $85.7 \%(n: 12)$ of these were minor complications, and $14.3 \%$ $(\mathrm{n}: 2)$ were major complications. Among these, hemorrhage ( $\mathrm{n}: 7 ; 9.5 \%$ ) was the most common minor complication. Hemorrhage was only in group II and group III. According to the SIR classification, minor complications include catheter dislocation ( $n: 4 ; 5.4 \%$ ), methemoglobinemia ( $n: 1 ; 1.4 \%$ ), major complications of pulmonary thromboembolism ( $\mathrm{n}: 1$; $1.4 \%$ ) and abdominal compartment syndrome ( $\mathrm{n}: 1 ; 1.4 \%)$ occurred.

The rate of emergency cholecystostomy need was $5.4 \%$ ( $n: 4)$ in general, and $7.7 \%(\mathrm{n}: 2)$ in group I, 7.7\% (n: 2$)$ in group II, $0 \%$ in group III $(p=0.409)$.

Elective cholecystostomy was required in 11 (42.3\%) patients in group I and 1 (3.8\%) in group II. In Group III, there was no need for elective cholecystostomy $(p<0.001)$. Elective cholecystostomy time was $79.1 \pm 10.1$ in group 1 and 65 days in group 2, respectively. None of these patients had perioperative complications or death.

Median length of hospital stay values were 6 days (5-9 days) in group I, 11 days (6-14 days) in group II, 9 days (7-16 days) in group III $(p=0.022)$. Only the median difference between group I and group II was statistically significant $(p=0.021)$. It was found that the duration of hospital stay increased with increasing age (rho: $0.230 ; p=0.049$ ).

There was a positive correlation between the patients' ASA score and $\mathrm{CCl}$ (rho: $0.715 ; \mathrm{p}<0.001$ ) and age (rho: 0.508; $\mathrm{p}$ $<0.001$, Table II).

Procedural mortality was not observed. Thirty- and 90-day mortality was similar with $9.6 \%$. The mean 30 -day survival group III was 24.6 days (SE: $1.024 ; 95 \mathrm{Cl}: 22.58-26.60$ ) and had a significantly higher mortality than group I $(p<0.001)$ and group II ( $p<0.001)$. There was no significant difference between the other groups.

The average 90-day survival group III was 70.9 days (SE: 7.061; 95Cl: 57.12-84.79) and had a significantly higher mortality than group I $(p=0.040)$ and group II $(p=0.045)$.

In the Multivariate Cox regression analysis, only ASA score was found to be an independent predictor in predicting overall survival (HR: 4.748; 95\% Cl: 1.030-21.895; $p=$ 0.046). When the effect of ASA on survival was examined by log-rank analysis, it was found that survival in the ASA 3 
group was higher than in the ASA 4 group (Log Rank (Mantel-Cox) $\chi 2$ : 14.749; $p<0.001$, Figure 1).

The need for revision was present in three patients (4.1\%), one patient in each group.

The mean time of catheter removal was $30.92 \pm 6.13$ days in group I, $36.96 \pm 9.58$ days in group II and $43.24 \pm 7.75$ days in group III. There was a statistically significant difference between all groups $(p<0.001)$. With increasing age, there was an increase in catheter removal time (rho: $0.588 ; p$ $<0.001)$ ). In addition, a significant positive correlation was found between catheter removal time and $\mathrm{CCl}$ (rho: 0.605; $\mathrm{p}$ $<0.001)$.

Median (min-max) overall follow-up was 357 (2-1426) days. Recurrent cholecystitis after catheter was seen in 6/67 (9\%) patients in total. Mean recurrence time, $88 \pm 9.5$ days, was 3 in group I, 2 in group II and 1 patient in group III. There was no statistically significant difference between the groups $(p=0.759)$.

\section{DISCUSSION}

Surgery is the gold standard treatment for AC, and aging is defined as a perioperative risk factor for cholecystectomy in the literature. ${ }^{13,14} \mathrm{PC}$ is a less invasive procedure compared to cholecystectomy in elderly patients or patients with high surgical risk due to comorbidities, and its use has gradually increased. ${ }^{11}$

The method of choice for the treatment of acute cholecystitis in geriatric and critically ill patients is still a controversial issue, and the number of studies evaluating geriatric age groups is limited in the literature. In a study conducted by Albir et al., only patients over the age of 70 were evaluated. ${ }^{15}$ The present study has the feature of being the first study in which age groups were evaluated in detail.

Technical success is generally stated as $90 \%$ and above in the literature; in this study, it was $100 \%$ as in the study by Bundy et al. ${ }^{16}$ In this study, there was a clinical success of over $90 \%$ in group I and group II. ${ }^{17}$ However, clinical success in Group III was proportionally less than other groups, and the authors think that this is more related to advanced age.

PC-related complication rates have been reported in the literature in a variable manner between 8 and $44 \%$. Studies performed with transhepatic and transperitoneal techniques in the literature were generally evaluated together and the complication rate was reported as $30.6 \%$ in the study of Horn et al. ${ }^{18}$ In this study, it was $18.9 \%$ and proportionally higher in groups II and III.

Although catheter displacement is the most common complication in the literature, it was hemorrhage in this study. Hemorrhage was observed in group II and group III, but not in group I. This may be associated with an increased suscepti- bility to bleeding diathesis, secondary to comorbidities such as increased age, renal failure and cirrhosis.

In a comprehensive review by Winbladh et al., $4.5 \%$ of the patients underwent emergency cholecystectomy due to treatment failure, recurrent cholecystitis or procedural complications. ${ }^{5}$ In this study, the need for urgent cholecystectomy was generally similar, and all were performed due to treatment failure. The rate in group III was significantly lower than the other groups.

Percutaneous cholecystostomy served as a bridge procedure to elective cholecystectomy in $21.8 \%$ of patients in the study of Horn et al. and in $40 \%$ of Winbladh et al. ${ }^{5,18}$ The need for elective cholecystectomy in Group I was consistent with the literature and was significantly higher than the other groups.

The 30 and 90 -day mortality was $10.16 \%-13.28 \%$, respectively, in the study of Albir et al., and was similar to this study. ${ }^{15}$ Group III had a significantly higher mortality than group I and group II. There was no significant difference between 30- and 90-day mortality. In the same study, it was affected by the prolongation of hospital stay, age of 70 , ASA-PS $\geq 3$ and the occurrence of complications. In this study, it was shown that the duration of hospital stay increased with increasing age.

The literature is not clear about the time of removal of the catheters, and it was stated that they can be removed 3-6 weeks after the procedure after cholecystitis has resolved. ${ }^{19}$ The time of catheter removal was the highest in group III. With increasing age, there was an increase in catheter removal time. In addition, there was a significant positive correlation between catheter removal time and $\mathrm{CCl}$. This may be related to the regression of cholecystitis findings and the maturation of the cystocutaneous fistula. Because aging has been shown in the literature as one of the factors that continuously affect the immune system in a generally harmful way. ${ }^{20}$

In this study, recurrence rate for the median 88 days after catheter removal was $9 \%$, lower than the $11.9 \%$ recurrence rate for the median of 62 days in the study by Pang et al. ${ }^{21}$ There was no difference between the groups. Since the study was more homogenous and transperitoneal, PC placement was associated with an increased risk of recurrence in the literature, the preference of patients with only transhepatic technique may have led to this recurrence difference.

The main limitations of this study were single-centre, retrospective, and very limited information about the exact time from the onset of acute cholecystitis symptoms to the onset of acute cholecystitis symptoms. It was also limited to short-term mortality.

\section{CONCLUSION}

PC is an effective and reliable method in elderly patients with acute cholecystitis with ASA $>3$ and (or) high $\mathrm{CCl}$. PC can be considered as definitive treatment in advanced elderly patients and interval therapy in early old age. 


\section{PATIENTS' CONSENT:}

Since the study was designed retrospectively, data were collected from clinical archives with the approval of the Ethics Committee.

\section{CONFLICT OF INTEREST:}

The authors declared no conflict of interest.

\section{AUTHORS' CONTRIBUTION:}

HG: Data collection, statistical analysis, software, data improvement, original draft writing, review writing and editing, final approval.

GD: Verification, critical revision, final approval.

\section{REFERENCES}

1. Alsuwaidan A, Almedlej N, Alsabti S, Daftardar O, Al Deaji $\mathrm{F}, \mathrm{Al}$ Amri $\mathrm{A}$, et al. A comprehensive overview of polypharmacy in elderly patients in Saudi Arabia. Geriatrics (Basel) 2019; 4(2):36. doi: 10.3390/geriatrics4020036.

2. Mazeh H, Mizrahi I, Dior U, Simanovsky N, Shapiro M, Freund HR, et al. Role of antibiotic therapy in mild acute calculus cholecystitis: A prospective randomised controlled trial. World J Surg 2012; 36(8):1750-9. doi: 10.1007/ s00268-012-1572-6.

3. Atar E, Bachar GN, Berlin S, Neiman C, Bleich-Belenky E, Litvin S, et al. Percutaneous cholecystostomy in critically ill patients with acute cholecystitis: complications and late outcome. Clin Radiol 2014; 69(6):247-52. doi: 10.1016/ j.crad.2014.01.012

4. Okamoto K, Suzuki K, Takada T, Strasberg MS, Asbun JH, Endo I, et al. Tokyo Guidelines 2018: Flowchart for the management of acute cholecystitis. J Hepatobiliary Pancreat Sci 2018; 25(1):55-72. doi: 10.1002/jhbp.516.

5. Winbladh A, Gullstrand P, Svanvik J, Sandstrom P. Systematic review of cholecystostomy as a treatment option in acute cholecystitis. HPB 2009; 11(3):183-93. doi: 10.1111/ j.1477-2574.2009.00052.x.

6. Ansaloni L, Pisano $M$, Coccolini $F$, Peitzmann $A B$, Fingerhut $A$, Catena $F$, et al. 2016 WSES guidelines on acute calculous cholecystitis. World J Emerg Surg 2016; (14)11:25. doi: 10.1186/s13017-016-0082-5.

7. Spira RM, Nissan A, Zamir O, Cohen T, Fields SI, Freund HR. Percutaneous transhepatic cholecystostomy and delayed laparoscopic cholecystectomy in critically ill patients with acute calculus cholecystitis. Am J Surg 2002; 183(1):62-6. doi: 10.1016/s0002-9610(01)00849-2.

8. Karakayali FY, Akdur A, Kirnap M, Harman A, Ekici Y, Moray G. Emergency cholecystectomy vs. percutaneous cholecystostomy plus delayed cholecystectomy for patients with acute cholecystitis. Hepatob Pancreat Dis Int 2014; 13(3):316-22. doi: 10.1016/s1499-3872(14)60045-x.

9. Kortram K, van Ramshorts B, Bollen TL, Besselink MGH, Gouma DJ, Karsten T, et al. Acute cholecystitis in high risk surgical patients: Percutaneous cholecystostomy versus laparoscopic cholecystectomy (CHOCOLATE trial): Study protocol for randomised controlled trial. Trials 2012; 13(12): 7. doi: 10.1186/1745-6215-13-7.

10. Sakran N. Kolpelman D, Dar R, Abaya N, Mokary SE, Handler C, et al. Outcome of delayed cholecystectomy after percutaneous cholecystostomy for acute cholecystitis. Isr Med Assoc J 2018; 20(10):627-31.

11. Lu P, Chan $C L$, Yang NP, Chang NT, Lin KB, Lai $K R_{\perp}$ et al. Outcome comparison between percutaneous cholecystostomy and cholecystectomy: A 10-year population-based analysis. BMC Surg 2017; 17(1):130. doi: 10.1186/ s12893-017-0327-6.

12. Yokoe M, Takada T, Strasberg SM, Solomkin JS, Mayumi T, Gomi H, et al. TG13 diagnostic criteria and severity grading of acute cholecystitis (with videos). J Hepatob Pancreat Sci 2013; 20(1):35-46. doi: 10.1007/s00534-012-0568-9.

13. Loozen CS, van Santvoort HC, van Duijvendijk P, Besselink MG, Gouma DJ, Nieuwenhuijzen GA, et al. Laparoscopic cholecystectomy versus percutaneous catheter drainage for acute cholecystitis in high risk patients (CHOCOLATE): Multicentre randomised clinical trial. BMJ 2018; 363:k3965. doi: 10.1136/bmj.k3965.

14. Nielsen LBJ, Harboe KM, Bardram L. Cholecystectomy for the elderly: No hesitation for otherwise healthy patients. Surg Endosc 2014; 28(1):171-7. doi: 10.1007/s00464-0133144-8.

15. Albir MG, Gorgojo VM, Perdomo R, Rodríguez JLM, Forner EM, Dorcaratto D, et al. Gastrointest Surg 2020; 24(11):2579-2586. doi: 10.1007/s11605-019-04424-5

16. Bundy J, Srinivasa RN, Gemmete JG, Shields JJ, Chick JFB. Percutaneous cholecystostomy: Long-term outcomes in 324 patients. Cardiovasc Intervent Radiol 2018; 41(6):928-4. doi: 10.1007/s00270-018-1884-5.

17. Baron TH, Grimm IS, Swanstrom LL. Interventional approaches to gallbladder disease. N Engl J Med 2015; 373(4):357-65. doi: 10.1056/NEJMra1411372.

18. Horn T, Christensen SD, Kirkegård J, Larsen LP, Knudsen AR, Mortensen FV. Percutaneous cholecystostomy is an effective treatment option for acute calculous cholecystitis: A 10year experience. HPB (Oxford) 2015; 17(4):326-31. doi: 10.1111/hpb.12360.

19. Abdulaal AF, Sharouda SK, Mahdy HA. Percutaneous cholecystostomy treatment for acute cholecystitis in high risk patients. Egypt J Radiol Nucl Med 2014; 45(4):1133-9. doi:10.1016/j.ejrnm.2014.07.001.

20. Vitlic A, Lord JM, Phillips AC. Stress, ageing and their influence on functional, cellular and molecular aspects of the immune system. Age (Dordr) 2014; 36(3):9631. doi: 10.1007/s11357-014-9631-6.

21. Pang KW, Tan CHN, Loh S, Chang KYS, Iyer SG, Madhavan $\mathrm{K}$, et al. Outcomes of percutaneous cholecystostomy for acute cholecystitis. World J Surg 2016; 40(11):2735-44. doi: 10.1007/s00268-016-3585-z. 